\title{
Real-Time Implementation of Brain Emotional Learning Developed for Digital Signal Processor-Based Interior Permanent Magnet Synchronous Motor Drive Systems
}

\author{
Mohamad-Ali Sadeghi ${ }^{*}$ and Ehsan Daryabeigi ${ }^{\dagger}$ \\ *Dept. of Electrical Eng., Sirjan Branch, Islamic Azad University, Sirjan, Iran \\ ${ }^{\dagger}$ Young Researchers and Elite Club, Najafabad Branch, Islamic Azad University, Najafabad, Isfahan, Iran
}

\begin{abstract}
In this study, a brain emotional learning-based intelligent controller (BELBIC) is developed for the speed control of an interior permanent magnet synchronous motor (IPMSM). A novel and simple model of the IPMSM drive structure is established with the intelligent control system, which controls motor speed accurately without the use of any conventional PI controllers and is independent of motor parameters. This study is conducted in both real time and simulation with a new control plant for a laboratory $3 \mathrm{ph}, 3.8 \mathrm{Nm}$ IPMSM digital signal processor (DSP)-based drive system. This DSP-based drive system is then compared with conventional BELBIC and an optimized conventional PI controller. Results show that the proposed method performs better than the other controllers and exhibits excellent control characteristics, such as fast response, simple implementation, and robustness with respect to disturbances and manufacturing imperfections.
\end{abstract}

Keywords: Intelligent control, Interior permanent magnet synchronous motor, Speed control, Vector control

\section{INTRODUCTION}

A traditional interior permanent magnet synchronous motor (IPMSM) has magnets embedded in the rotor core, a mechanically robust rotor construction, rotor non-saliency, and a small effective air gap. These features allow the IPMSM drive to operate in a wide range of speed modes [1], [2].

High-performance motor drives usually require a fast and accurate response, rapid recovery from any disturbances, and insensitivity to parameter variations. The dynamic behavior of an $\mathrm{AC}$ motor can be significantly improved by vector control theory [1]. This theory provides the IPMSM machine the highly desirable dynamic performance capabilities of a separately excited DC machine while retaining the general advantages of the AC motor over the DC one. Another drive method is direct torque control (DTC), which has a number of attractive features, such as minimal parameter dependence,

Manuscript received Sep. 2, 2013; revised Sep. 20, 2013

Recommended for publication by Associate Editor Sanjeet K. Dwivedi.

${ }^{\dagger}$ Corresponding Author: e.daryabeigi@gmail.com

Tel: +983312291111, Najafabad Branch, Islamic Azad University

*Dept. of Electrical Eng., Sirjan Branch, Islamic Azad University, Iran fast dynamic response, and no requirement for a mechanical rotor position sensor for the inner torque control loop [3], [4]. However, some problems or limitations have been associated with this control method as follows: 1) drift in stator flux linkage estimation because of the offset error in measurement; 2) error in the estimation of stator flux linkage resulting from the variation in stator resistance; and 3) requiring a mechanical position sensor to detect the initial rotor position [5]. Addressing these problems or limitations requires the use of other methods and thus causes the system to become complex [6]. Moreover, the precise speed control of an IPMSM drive becomes complex because of the nonlinear coupling among its winding currents and the rotor speed as well as the nonlinearity present in the torque equation.

Considerable developments have been made in nonlinear control theories that are applicable to electric motor drives [7]. Interestingly, the d-q transformation applicable to AC motors can be considered a feedback-linearization transformation. With the recent developments in nonlinear control theories, modern control engineers have not only established a systematic approach to deal with nonlinear connections but have also managed to develop approaches that were not 
considered previously. These nonlinear control methods applicable to electromechanical systems include variable structure systems approach [3], differential geometric approach, [7] and passivity theory [8]. However, most of the controllers in these methods are complex and costly. Thus, designing a controller that performs well and costs less is important.

Intelligent methods have been used recently to solve the problems discussed in [2], [6], [9]-[19]. Artificial intelligence (AI) techniques have recently been applied in power electronics and motor drives [10]. AI techniques aim to implant human or natural intelligence in a computer so that this computer can think intelligently. A system with embedded computational intelligence is often defined as an "intelligent system" that has a "learning," "self-organizing," or "self-adapting" capability.

Despite the versatility of bio-inspired and intelligent systems, many practical applications require large computational power to overcome the complexity and real-time constraints of these systems. In addition, dedicated systems are necessary in many industrial applications to meet low power and space requirements [9], [11]. Some of these systems cannot implement the control process without any previous learning [11], whereas others are based on rules [12]. An intelligent robust control system has been developed recently for precision tracking control [13]; the system exhibits good performance. However, this method is extremely complex and difficult to implement.

Several attempts have been made to model the emotional behavior of the human brain [14]. In [15], computational models of the amygdala and context processing were introduced; these models are called brain emotional-learning (BEL) models. However, these models have not been used in any practical area, particularly in engineering applications. The BEL-based intelligent controller (BELBIC) was first introduced by Lucas in 2004 [14] based on the cognitively motivated open-loop model. This controller has been employed in control devices for several industrial applications over the past few years [16]-[25]. In [16], BELBIC was utilized to control a laboratorial overhead traveling crane in a model-free and embedded manner. In [17], the speed of a highly non-linear IPMSM was controlled with a conventional BELBIC. Flux and speed control of the induction motor was implemented in [18]. Controller operation was investigated in [19] by the variations in motor parameters, such as the rotor resistor.

The abovementioned evidence on the use of emotional control approaches in computers and control engineering indicates that the application of emotions in systems can effectively overcome the problems of non-linear systems. Thus, the emotional controller in high-performance electric drives, such as IPMSM, is selected and developed as a suitable speed controller.
This paper is organized as follows. The IPMSM drive model in the d-q reference frame is presented in Section II. The structure of the novel intelligent controller based on medial brain and its emotional learning are explained in Section III. The block diagrams of the control system and hardware setup are described in Section IV. The simulation results are presented and discussed in Section V. The conclusion is provided in Section VI.

\section{MATHEMATICAL MODEL OF IPMSM}

The mathematical model of an IPMSM drive in a synchronously rotating rotor $\mathrm{d}-\mathrm{q}$ reference frame can be described by the following equations [17]:

$$
\begin{gathered}
{\left[\begin{array}{c}
v_{d} \\
v_{q}
\end{array}\right]=\left[\begin{array}{cc}
r_{s}+D L_{d} & -P w_{r} L_{q} \\
P w_{r} L_{d} & r_{s}+D L_{q}
\end{array}\right]\left[\begin{array}{l}
i_{d} \\
i_{q}
\end{array}\right]+\left[\begin{array}{l}
0 \\
P w_{r} \psi_{f}
\end{array}\right]} \\
T_{e}=T_{L}+J_{m} D w_{r}+B_{m} w_{r} \\
T_{e}=\frac{3 P}{2}\left[\psi_{f} i_{q}+\left(L_{d}-L_{q}\right) i_{d} i_{q}\right]
\end{gathered}
$$

where $i_{q}, v_{q}, r_{s}, \omega_{r}, \psi_{f}, T_{e}, T_{l}, B$, and $J_{m}$ denote the current q-axis, voltage q-axis, rotor speed, magnetic flux, electromagnetic torque, load torque, friction coefficient, and inertia moment, respectively. A synchronous motor is clearly unable to self-start when supplied with a constant frequency source. A rotor squirrel cage winding generates the required starting torque in the IPMSM drive fed from the mains. The starting process of the IPMSM drive can be considered a superposition of two operating modes, namely, unsymmetrical asynchronous motor mode and permanent magnet-excited synchronous generator mode [17]. Therefore, the effects of the shorted rotor windings must be considered when attempting to implement synchronization. However, the model in Equations (1) to (3) does not describe the asynchronous behavior of the IPMSM drive because the motor is fed by a variable frequency inverter. Varying the residual flux density and stator resistance as the operating temperature affects the dynamic behavior of the motor controller. The use of the standard linear d-q axis IPMSM model with constant parameters will lead to an unsatisfactory prediction of the performance of a permanent-magnet motor because of the saturation of these machines during normal operation. The prediction of IPMSM behavior can be improved by adjusting the model parameters according to the changing saturating conditions [20]. Various researchers have reported that variations exist in $X_{d}, X_{q}$, and $\psi_{f}$ with direct and quadratic axis saturation as well as with the direction of rotation $[17,20]$. In light of these findings, we propose the use of the developed BELBIC, which responds to all of these variations in the drive system. This study aims to 


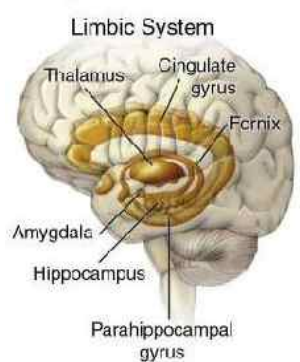

Fig. 1. Sectional view of the human brain for emotion processing.

determine the IPMSM control currents to achieve high-performance speed and torque tracking. In this regard, that the proposed BELBIC can receive the error of speed and then generate $i_{q}$ as the control signal as long as d-axis current $i_{d}=0$ is maintained. However, in a previous control plant [17], according to the motor model provided in Equations (1) to (3) of Section II, speed control can be achieved by controlling q-axis component $v_{q}$ of the supply voltage as long as d-axis current $i_{d}=0$ is maintained. This process results in electromagnetic torque being directly proportional to current $i_{q}$. Since $i_{d}=0$, the d-axis flux linkage depends only on the rotor permanent magnets. The resultant IPMSM model can be represented as

$$
\begin{gathered}
D i_{q}=\frac{1}{L_{q}}\left(v_{q}-r_{s} i_{q}-P w_{r} \psi_{f}\right) \\
v_{d}=P w_{r} L_{q} i_{q} \\
T_{e}=\frac{3 P}{2}\left(\psi_{f} i_{q}\right)=K_{T} i_{q} \\
w_{r}=\frac{K_{T} i_{q}-T_{L}}{\left(J_{m} D+B_{m}\right)}
\end{gathered}
$$

where $K_{T}$ is the torque constant. The IPMSM characteristics are provided in the Appendix.

\section{COMPUTATIONAL MOdEL OF THE EMOTIONAL SYSTEM}

The decision mechanism in the brain includes two main parts, namely, cognitive and conceptual sciences, which are found in the upper cortex and medial brain, respectively. Emotional learning as the fastest decision mechanism in the brain is a subset of conceptual sciences [15]. Motivated by the successful functional modeling of emotions in control engineering applications in [14], [15], and [16], this study employs a structural model based on the limbic system of the mammalian brain for decision-making and control engineering applications. The network model

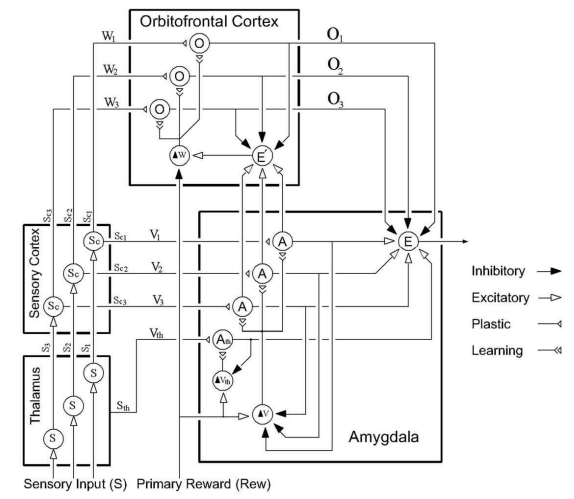

Fig. 2. Graphical depiction of the developed computational model of BELBIC.

developed by Moren and Balkenius [15], which is a computational model that mimics the amygdala, orbitofrontal cortex, thalamus, sensory input cortex, and other parts of the brain generally thought to be responsible for processing emotions, is adopted as shown in Fig. 1. The intelligent system, the computational model called BELBIC, is used as the controller block [14]. For simplicity, BELBIC is referred to as the emotional controller in this paper. The BELBIC technique is essentially an action-generation mechanism based on sensory inputs and emotional cues. These sensory inputs and emotional cues can be vector valued. However, only one sensory input and one emotional signal (stress) are considered and illustrated in this study.

Emotional learning occurs mainly in the amygdala. The amygdala is a part of the brain responsible for processing emotions; it is connected to the orbitofrontal cortex, the thalamus, and the sensory input cortex (Fig. 3). The amygdala and orbitofrontal cortex form a network structure in the computational model wherein each part is internally connected to the other in lieu of each sensory input. Another connection exists between the thalamus input and the amygdala. The value of this input is equal to the maximum sensory input value in Equation (8). In Fig. 2, one $A$ node exists for every stimulus $S$, including one for the thalamic stimulus. One $O$ node exists for each of the stimuli, except for that in the thalamic node. One output node $E$ that is common to all the outputs of the model likewise exists.

The result is the output from the model. Thus, $E$ can be obtained from

$$
E=\sum_{j} A_{j}+A_{t h}-\sum_{j} O_{j}
$$

The internal areas outputs are computed based on Equations (8) to (11).

$$
\begin{gathered}
A_{t h}=V_{t h} \cdot\left\{\max \left(S_{j}\right)=S_{t h}\right\} \\
A_{j}=S_{j} V_{j}, O_{j}=S_{j} W_{j} \\
S c_{j}=S_{j} \otimes\left\lfloor e^{-k \cdot t}\right\rfloor
\end{gathered}
$$




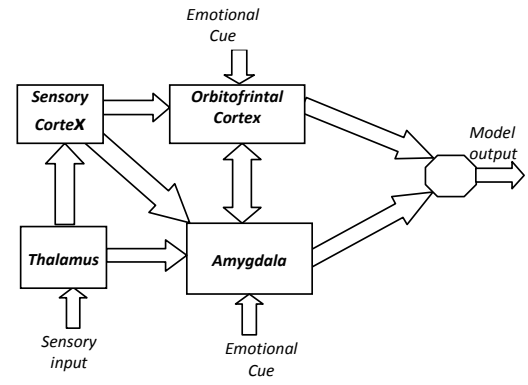

Fig. 3. Abstract structure of the computational model that mimics some parts of the mammalian brain.

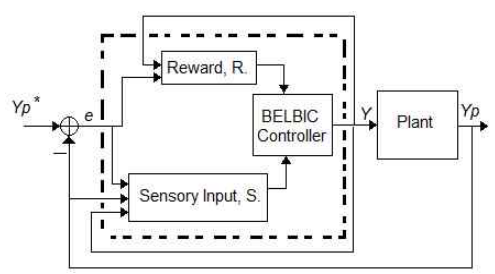

Fig. 4. Control system configuration using BELBIC.

where $A_{j}$ and $O_{j}$ are the values of the amygdala output and the output of the orbitofrontal cortex at each time, respectively; $V_{j}$ is the gain in the amygdala connection; $W_{j}$ is the gain in the orbitofrontal connection; $S_{j}$ and $S_{C_{j}}$ are sensory input and sensory-cortex output, respectively; and $j$ is input $j$ th.

The variations in $V_{j}$ and $W_{j}$ can be calculated as

$$
\begin{aligned}
& v_{i}^{\prime}=\alpha\left(\max \left(0, S c_{i}\left(R-\sum_{i} A_{i}\right)\right)\right. \\
& V_{i}=\int_{0}^{t} v_{i}^{\prime} d t+V(0) \\
& v_{t h}^{\prime}=\alpha_{t h}\left(\max \left(0, S_{t h}\left(R-A_{t h}\right)\right)\right. \\
& V_{t h}=\int_{0}^{t} v_{t h}^{\prime} d t+V_{t h}(0)
\end{aligned}
$$

Likewise, the $E^{\prime}$ node sums the outputs from $A$ except $A_{t h}$ and then subtracts from the inhibitory outputs of the $O$ nodes.

$$
\begin{gathered}
E^{\prime}=\sum_{j} A_{j}-\sum_{j} O_{j} \\
w_{i}^{\prime}=\beta\left(S c_{i}\left(E^{\prime}-R\right)\right) \\
W_{i}=\int_{0}^{t} w_{i}^{\prime} d t+W(0)
\end{gathered}
$$

where $\left(\alpha, \alpha_{t h}\right)$ and $\beta$ are the learning steps in the amygdala and orbitofrontal cortex, respectively. $R$ is the value of the emotional cue function at each time. $A_{j}$ values cannot decrease, which means that forgetting information does not occur in the amygdala because "forgetting" or inhibiting is the duty of the orbitofrontal cortex. Eventually, the model output is obtained from Equation (7).
Fig. 4 shows the BELBIC controller configuration. The functions utilized in emotional cue $R$ and sensory input $S$ blocks can be expressed by the following equations:

$$
\begin{aligned}
& S=k_{1} e+k_{2} \int e d t, \quad S_{t h}=k_{1} e \cdot\left|\int e . d t\right| \\
& R=K_{1}|e|+K_{2}|e \cdot y|+0.5 \max \left(\left(\left|y_{p}\right|-y_{\text {Max }}\right), 0\right)
\end{aligned}
$$

where $\boldsymbol{e}, E, y_{p}$, and $y_{\text {Max }}$ denote the system error, controller output, system output, and maximum output, respectively. $k_{1}, K_{1}, k_{2}$, and $K_{2}$ are constant gains, which must be tuned to design a satisfactory controller. The initial values for $\alpha$ and $\beta$ in $O$ and $A$, which also function as $R$ and $S$, are selected for proper emotional signal generation.

The proposed BELBIC is developed with Equation (11) to model the thalamus and by separating learning of the thalamic stimulus from that of the sensory cortex stimulus in the amygdala [Equations (12) and (13)]. The Wikipedia website [21] provides additional details.

\section{IPMSM DRIVE CONTROL SYSTEM}

\section{A. Proposed Drive Control}

Fig. 5(a) shows the block diagram of the new control system that incorporates the emotional controller (BELBIC). The emotional control system receives the error signals between the command speed and the actual motor speed as part of inputs according to Equations (12) to (16) and generates the output signals according to Equations (8) to (11). In this control design, the emotional intelligent controller receives the speed error as input and generates $i_{q}^{e}$ as output; $i_{d}^{e}=0$. These input and output are in the rotating reference frame oriented to the rotor flux and are then transferred to a stationary reference frame. By using $i_{d}^{s}$ and the pre-calculated $i_{q}^{s}$, the command a-b-c phase currents $i_{a}^{s^{*}}, i_{b}^{s^{*}}, i_{c}^{s^{*}}$ are generated with inverse Park's transforms. The hysteresis current controller is used to implement the vector control algorithm. The current controller compares the command currents with the corresponding actual motor currents and generates the logic signals to command the inverter switches [18].

According to the abovementioned control procedure, the control plant controls the motor without using other conventional controllers (such as PI controllers) and is relatively independent of motor parameters. This finding is important in designing power drive control plants.

However, based on a previous control plant of BELBIC (Rahman's model in [17]), the controller receives the error signals between the command speed and the actual motor 
speed as part of the input and generates the output signal. The controller output is $v_{q}$ according to the simplified model obtained with Equations (4) to (7) and the controller model obtained with Equations (8) to (20). From controller output $v_{q}$, command quadratic axis current component $I_{q c}$ can be calculated according to the motor model obtained with Equations (4) to (7); thus, the design does not directly generate $I_{q c}$.

\section{B. Hardware system}

A conventional digital-control platform based on the eZdsp F2812 board, which is a suitable platform for implementing motor controllers, is employed in this study.

This board is built around the TMS320F2812 digital signal processor (DSP). This platform is compatible with Simulink and includes three dual pulse-width modulation (PWM) channels (six channels in total), four analog-to digital converters (ADCs), and a speed-encoder input. The processor is a 32-bit DSP with fixed-point arithmetic. Thus, discrete and fixed-point math blocks from Simulink can be utilized to program the processor. The complete experimental hardware utilized to evaluate the 3-ph, $3.8 \mathrm{Nm}$ IPMSM drive shown in Fig. 6.

\section{RESULTS AND DISCUSSION}

To evaluate the emotional controller and assess the effectiveness and control capability of the proposed BELBIC scheme, the performance of the IPMSM drive based on the proposed control scheme is investigated by conducting both simulation and experimental tests at different operating conditions. For further evaluation and fair judgment, the same tests are performed to operate the optimal conventional controller PI (OCC), which is then compared with the proposed BELBIC controller. The controller PI is optimized by a new optimization algorithm called Smart Bacteria Foraging Algorithm (SBFA) [22]. The speed control loop is optimized under constant conditions of speed $(+188.4 \mathrm{rad} / \mathrm{s}$, no loading), with focus on the cost function (integration of the absolute value of torque-producing speed error $|E|$ ). Fig. 7 shows the running algorithms. The cost function is provided by

$$
J=\int_{t_{1}=0}^{t_{2}}|E| d t
$$

The parameters achieved by SBFA for the flux and speed PI controllers (OCC-PI) are shown in the Appendix.

Digital computer simulations are performed with Matlab/Simulink [23]. The simulated responses, which are shown in Figs. 8 to 10 , are utilized to investigate system tracking. The drive system is initialized and operated according to the flowing sequence in the following tests.

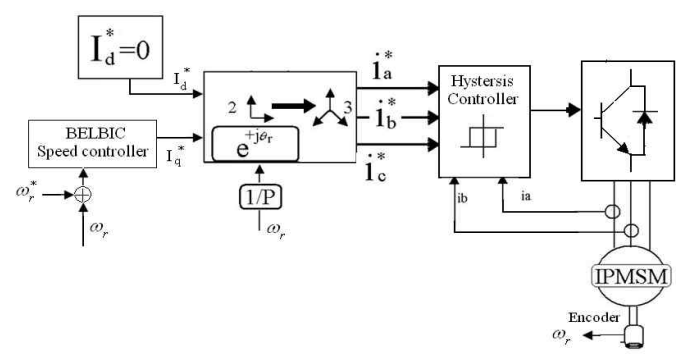

Fig. 5. Proposed control system structure of the IPMSM drive with BELBIC based on vector control.

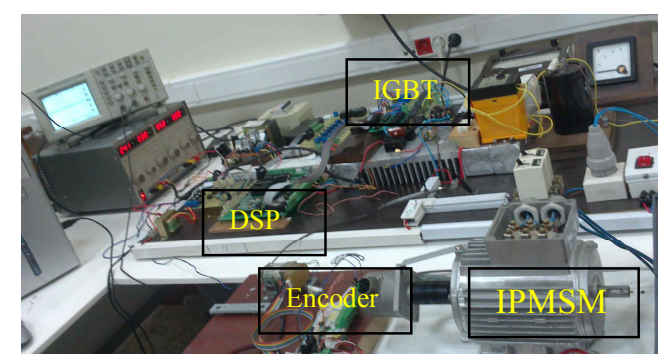

Fig. 6. Hardware implementation of the proposed controller.

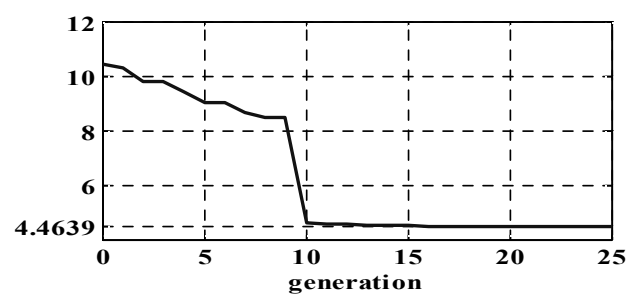

Fig. 7. Convergence of the cost function in SBFA, which is equal to 4.46399761 .

TABLE I

REFERENCE COMMANDS FOR TEST 1

\begin{tabular}{|c|c|c|c|c|c|}
\hline Time $[\mathrm{sec}]$ & 0 & 0.07 & 0.27 & 0.3 & 1 \\
\hline$\omega_{r}^{*}[\mathrm{rad} / \mathrm{s}]$ & 0 & 188.4 & 188.4 & 188.4 & 188.4 \\
\hline
\end{tabular}

\begin{tabular}{|c|c|c|c|c|c|c|c|}
\hline Time [sec] & 0 & 0.07 & 0.27 & 0.3 & 0.3 & 0.5 & 1 \\
\hline$T_{L}[\mathrm{Nm}]$ & 1 & 1 & 1 & 1 & 2.5 & 2.5 & 2.5 \\
\hline
\end{tabular}

Test 1: The flow of the speed and load torque commands is shown in Table I.

As shown in Fig. 8, the control system performs well with BELBIC. The actual speed tracks its reference, and the stator current is lower than its rated value. Thus, the increase time of the stator current is less than $10 \mathrm{~ms}$.

The rotor speed, electromagnetic torque, stator current and control signal $1 i_{q}^{e^{*}}$ in BELBIC are shown in Figs. 8(a), 8(b), 8(c), and 8(d), respectively. Fig. 9 shows the simulation results obtained with the OCC-PI control. A steady-state error as well as higher torque ripple and lower dynamic than BELBIC are observed. Rotor speed and electromagnetic torque are shown in Figs. 9(a) and 9(b), respectively. During loading, the control system cannot 

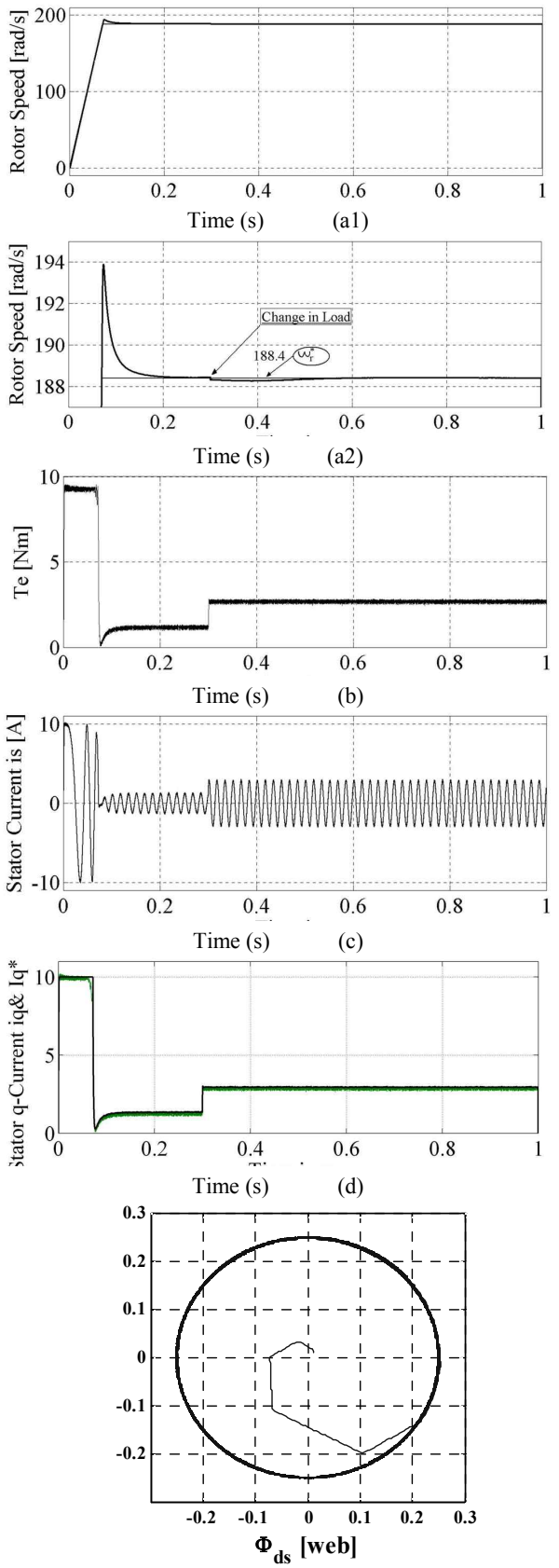

(e)

Fig. 8. Simulation results for IPMSM control using BELBIC. Test 1: a) motor speed, b) electromagnetic torque, c) steady-state stator current phase-a, d) control signal $i_{q}^{e^{*}}$ and stator q-current $i_{q}$, and e) stator flux curve.

maintain its own robustness unlike the proposed system, which exhibits good performance during loading in terms of robustness [Fig. 8(a2)]. The results for the previous design of BELBIC are shown in Fig. 10. As shown in Fig. 10(a), the rotor speed tracks the reference with a transient response of approximately $10 \mathrm{~ms}$ and an overshoot. The proposed version of BELBIC generates a faster response compared with the previous one. As shown in Fig. 5, the proposed
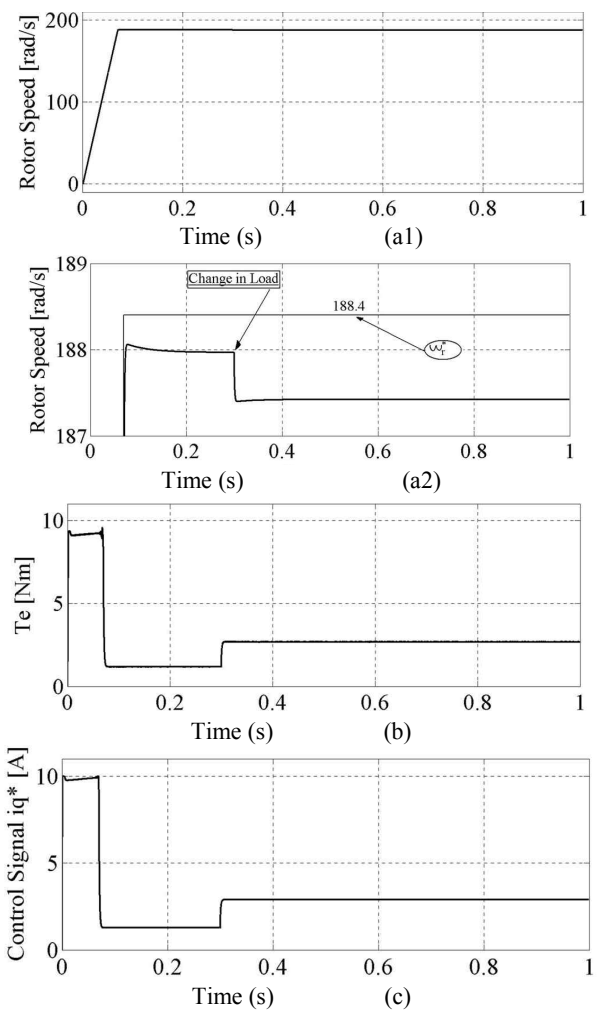

Fig. 9. Simulation results for IPMSM control using PID. Test1: a) motor speed and b) electromagnetic torque.
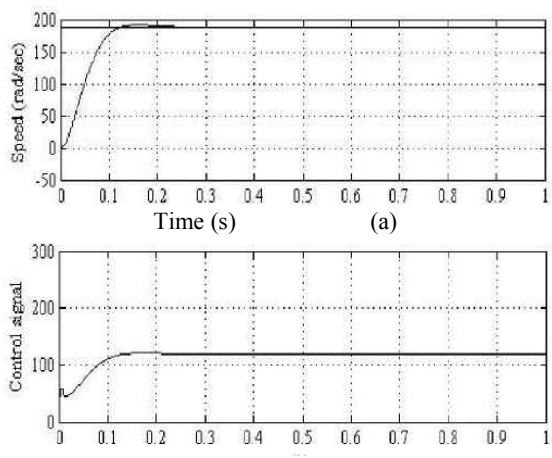

Time (s) (b)
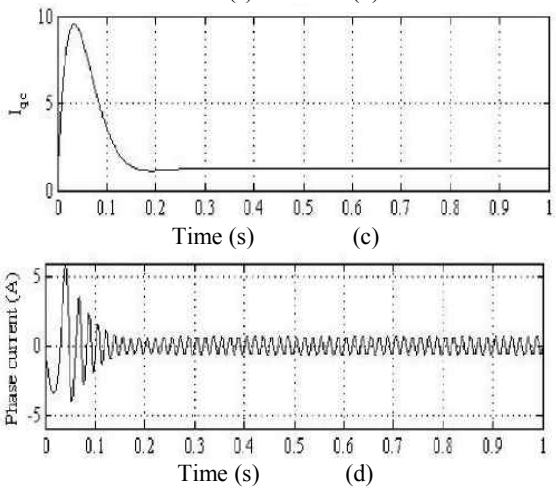

Fig. 10. Speed control of IPMSM using the emotional controller reported in [22]. (a) Command and motor speeds, (b) control signal, (c) torque current component, and (d) motor phase current. 


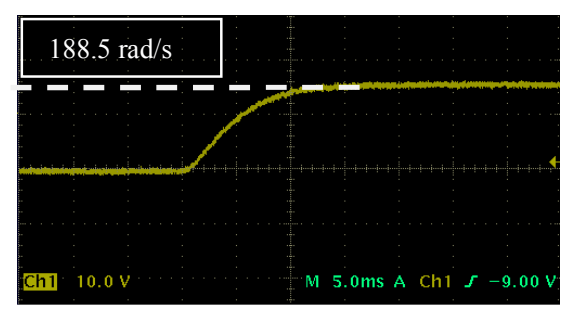

(a)

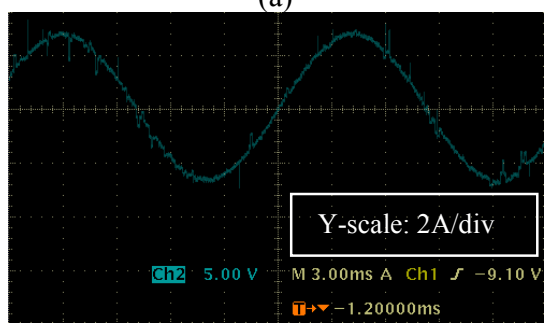

(b)

Fig. 11. Experimental results obtained with proposed BELBIC in speed control mode. a) Rotor speed and b) stator current.

structure directly controls the plant without using any conventional PI or calculating parameters. The experimental results achieved with the proposed BELBIC are presented in Fig. 11; these results confirm those of the simulation shown in Fig. 8. Thus, the rotor speed benefits from a soft start without any overshoot and makes the rise time shorter than $10 \mathrm{~ms}$.

\section{CONCLUSIONS}

The performance of BELBIC as the speed controller of an IPMSM was demonstrated. Simulation and real-time implementations were performed to verify the effectiveness of the new emotional controller (BELBIC). The performance of the emotional controller was compared with those of the previous version of the BELBIC controller and OCC-PI controller. Compared with OCC-PI, the proposed method exhibited better performance in terms of transient response and robustness of operation under loading conditions. The proposed approach also outperformed the previous version of BELBIC in transient state because the former exhibited a faster response without any overshoot. The proposed emotional controller has a number of advantages, including the freedom to select desired responses in terms of overshoot, settling time, steady-state error, and smoothness. These advantages make the emotional controller effective and flexible in high-performance applications. Moreover, the simple structure, fast auto learning, and high tracking potency of BELBIC were utilized to present a new control plant that is independent of motor parameters and eliminates the use of conventional PI controllers. These features make BELBIC an ideal candidate for industrial-level implementation.
APPENDIX

TABLE II

COEFFICIENTS OF OCC-PI

\begin{tabular}{|c|c|c|}
\hline Control Loop & $K_{P}$ & $K_{i}$ \\
\hline Speed Controller & 2.4664 & 0.108638 \\
\hline
\end{tabular}

TABLE III

PARAMETERS of BELBIC

\begin{tabular}{|c|c|c|c|c|c|c|c|}
\hline$\alpha$ & $2 \mathrm{e}-3$ & $\alpha_{\text {th }}$ & $6 \mathrm{e}-3$ & $\beta$ & $2 \mathrm{e}-3$ & $K_{1}$ & 0.25 \\
\hline$k_{1}$ & 0.072 & $k_{2}$ & 0 & $K_{2}$ & 0.042 & & \\
\hline
\end{tabular}

TABLE IV

PARAMETER TABLE OF THE IPMSM DRIVE

\begin{tabular}{|c|c|c|c|}
\hline Pole & Frequency & $\begin{array}{c}\text { Stator } \\
\text { resistance }\end{array}$ & $\begin{array}{c}\text { Stator current } \\
\text { rated }\end{array}$ \\
\hline 4 & $60 \mathrm{~Hz}$ & $6 \mathrm{ohm}$ & $1.7 \mathrm{~A}$ \\
\hline $\begin{array}{c}\text { Phase } \\
\text { number }\end{array}$ & $\begin{array}{c}\text { Torque } \\
(\max )\end{array}$ & Voltage rated & $\begin{array}{c}\text { Torque } \\
\text { constant }\end{array}$ \\
\hline 3 & $3.8 \mathrm{Nm}$ & $208 \mathrm{~V}$ & $0.8 \mathrm{Nm} / \mathrm{A}$ \\
\hline $\begin{array}{c}0.0002 \\
\mathrm{~kg} \mathrm{~m}^{\wedge} 2\end{array}$ & Rotor inertia & \multicolumn{3}{|c}{} \\
\hline
\end{tabular}

\section{REFERENCES}

[1] F. Blaschke, "The principle of field orientation as applied to the new transvector closed-loop control system for rotating-field machines," Siemens Reviews., Vol. 34, pp. 217 220, May 1972.

[2] M. Nasir, M. Uddin, and M. A. Rahman, "High-speed control of ipmsm drives using improved fuzzy logic algorithms", IEEE Trans. on Indus. Electron., Vol. 54, No. 1, pp. 190-199, Feb. 2007.

[3] Utkin, V., Sliding Modes in Control Optimization: Springer Verlag, 1992.

[4] M. F. Rahman, I. Zhong, and K. W. Lim, "A direct torque controlled interior magnet synchronous motor drive incorporating field weakening," IEEE Trans. Ind. Applicat., Vol. 34, pp. 1246-1253, Nov./Dec. 1998.

[5] M. F. Rahman, M. E. Haque, L. Tang, and L. Zhong, "Problems associated with the direct torque control of an interior permanent-magnet synchronous motor drive and their remedies", IEEE Trans, on Ind. Electron., Vol. 51, No. 4, pp. 799-809, Aug. 2004.

[6] Y. V. S. Reddy, M. V. Kumar, T. B. Reddy, and J. Amarnath, "Direct torque control of induction motor based on state feedback and variable structure fuzzy, controllers," in Proceeding of IEEE Conf., 2006.

[7] M. A. Rahman, M. Vilathgamuwa, M. N. Uddin, and K. J. Tseng, "Nonlinear control of interior permanent magnet synchronous motor," IEEE Trans. Ind. Appl., Vol. 39, No. 2, pp. 408-416, Mar./Apr. 2003.

[8] R. Ortega, P. J. Nicklasson, and G. Espinosa, "Passivity-based control of a class of Blondel-Park transformable electric machines," IEEE Trans. Automat. Contr., Vol.42, pp. $629-647,1997$.

[9] B. K. Bose, "Neural network applications in power electronics and motor drives-An introduction and 
perspective," IEEE Trans. Ind. Electron, Vol. 54, No. 1, pp. 14-33, Feb. 2007.

[10] T. Orlowska-Kowalska and K. Szabat, "Control of the drive system with stiff and elastic couplings using adaptive neuro-fuzzy approach," IEEE Trans. Ind. Electron. Vol. 54, No. 1, pp. 228-240, Feb. 2007.

[11] M. R. G. Magali, P. E. M. Almeida, and M. G. Simões, "A comprehensive review for industrial applicability of artificial neural networks," IEEE Trans. Ind. Electron. Vol. 50, No. 3, Jun. 2003.

[12] B. K. Bose, "Expert system, fuzzy logic, and neural network applications in power electronics and motion control," in Proceeding of IEEE, Vol. 82, pp. 1303-1323, Aug. 1994.

[13] F. F. M. El-Sousy, "Robust recurrent wavelet interval type-2 fuzzy-neural-network control for dsp-based pmsm servo drive systems," Journal of Power Electronics, Vol. 13, No. 1, pp. 139-160, Jan. 2013.

[14] C. Lucas, D. Shahmirzadi, and N. Sheikholeslami, "Introducing BELBIC: brain emotional learning based intelligent control," International Journal of Intelligent Automation and Soft Computing, Vol. 10, No. 1, PP. 11-22, 2004.

[15] J. Moren and C. Balkenius "A computational model of emotional learning in the amygdala," From animals to animals 6: in Proceedings of the International conference on the simulation of adaptive behavior"

[16] M. R. Jamali, M. Dehyadegari, A. Arami, C. Lucas, and Z. Navabi, "Real-time embedded emotional controller," $J$. Neural Comput. Appl., Vol. 19, 507, No. 1, pp. 13-19, Feb. 2010.

[17] M .A. Rahman, R. M. Milasi, C. Lucas, B. N. Arrabi, T. S. Radwan, "Implementation of emotional controller for interior permanent magnet synchronous motor drive," IEEE Trans. Ind. Applicat., Vol. 44, No. 5, pp. 1466-1476, Sep. /Oct. 2008.

[18] G. R. Arab Markadeh, E. Daryabeigi, M. A. Rahman, and C. Lucas," Speed and flux control of induction motors using emotional intelligent controller," IEEE Trans. Ind. Appl. Vol. 47, No. 3, pp. 1-10, May/Jun. 2011.

[19] E. Daryabeigi, G. Arab Markade, and C. Lucas, "Simultaneously, speed and flux control of a induction motor, with brain emotional learning based intelligent controller (BELBIC)," in Proceeding of IEEE, IEMDC, pp 894 - 901, May. 2009.

[20] T. S. Radwan, M. A. Rahman, A. M. Osheiba, and A. E. Lashine, "Dynamic analysis of a high performance permanent magnet synchronous motor drive," in proceeding IEEE Canadian Conference in Electrical and Computer Engineering, pp. 611-614, 1996.
[21] Wikipedia-BELBIC-http://en.wikipedia.org/wiki/BELBIC, Oc. $6^{\text {th }}, 2013$.

[22] A. Khodabakhshian, E. Daryabeigi, and M. Moazzam, “A new optimization approach for multi-machine power system stabilizer design using a smart bacteria foraging algorithm," SIMULATION: TSMSI. Vol. 89, No. 9, pp.1041-1055, 2013.

[23] Matlab, Simulink User Guide The Math works Inc., Natick, MA, 2003.

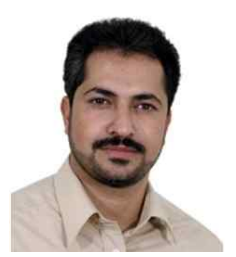

Mohamad-Ali Sadeghi was born in Baft, Iran. He received his B.S. degree in electrical engineering from Kerman University, Kerman, Iran, in 1996 and his M.S. degree in electrical engineering from the University of Tehran, Tehran, Iran, in 2011. From 1996 to 2010, he was with the Kerman Institute of Technology, Kerman, Iran, where he worked on the development of power electronic applications. He is currently a university lecturer in the Department of Electrical Engineering, Kerman University Technical Vocational, Kerman, Iran. His research interests include FACTS devices in transmission power systems and power electronic applications in electromotor fields.

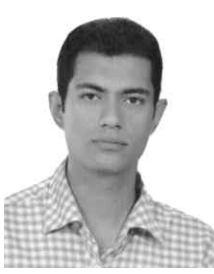

Ehsan Daryabeigi was born in Sirjan, Iran, in 1983. He received his B.Sc. degree in electrical engineering from $I A U$ University, Yazd branch, in 2005 and his M.Sc. degree in electrical engineering from $I A U$ University, Najafabad branch, in 2009.

He has been with the University of Tehran as an associate researcher in its Advanced Motion Control Laboratory since 2011. His research interests include applications of advanced control and optimization techniques in electric drive control, power electronics, and power systems. His research is mainly focused on developing bio-inspired algorithms (inclusive of intelligent controls and optimization methods) and their use in engineering applications. He has been a student member of Young Researchers and Elite Club since 2008, a graduate student member of IEEE since 2009, and a member of the American Association for the Advancement of Science since 2012. Furthermore, he has been a reviewer for the Journal of Intelligent \& Fuzzy Systems since 2013. 